\title{
Index des experts
}

\section{Expert's index}

(C) Springer-Verlag France 2013

La rédaction d'Acta Endoscopica remercie chaleureusement les experts qui ont accepté de relire et commenter les articles originaux publiés dans la revue en 2012 et 2013.

Karl Barange

Christian Boustière

Paul Castellani

Christophe Cellier

Franck Cholet

Emmanuel Coron

Jean-Charles Delchier

Patrick Faure

Rodica Gincul

Jean-Marc Gornet
Philippe Grandval

Denis Heresbach

Arthur Laquière

Antoine De Leusse

Vincent Maunoury

Bertrand Pujol

Gabriel Rahmi

Xavier Treton

Geoffroy Vanbiervliet

Frank Zerbib 